\title{
Habitat Suitability \& Connectivity of Alborz Wild Sheep in the East of Tehran, Iran
}

\author{
Zeinab Yeganeh Keya ${ }^{*}$, Shahrzad Faryadi², Ahmadreza Yavari², Yahya Kamali, \\ Afshin Alizadeh Shabani ${ }^{4}$ \\ ${ }^{1}$ Faculty of Environment, University of Tehran, Tehran, Iran \\ ${ }^{2}$ Department of Environmental Planning, Faculty of Environment, University of Tehran, Tehran, Iran \\ ${ }^{3}$ Department of Political Science, Faculty of Law and Theology, Bahonar University of Kerman, Kerman, Iran \\ ${ }^{4}$ Department of Environment, Faculty of natural resources, University of Tehran, Karaj, Iran \\ Email: *yeganehkeya@ut.ac.ir
}

Received 26 April 2016; accepted 10 May 2016; published 13 May 2016

Copyright (C) 2016 by authors and Scientific Research Publishing Inc.

This work is licensed under the Creative Commons Attribution International License (CC BY).

http://creativecommons.org/licenses/by/4.0/

(c) (i) Open Access

\section{Abstract}

Habitat loss and fragmentation of the wildlife species due to anthropogenic developments have been becoming serious issues in biological conservation. Alborz wild sheep, listed as threatened by IUCN, is distributed in relatively small and isolated patches in an increasingly human dominated landscape in the north-central Iran and east of Tehran. We used maximum entropy modeling to identify habitat areas of the wild sheep, across Jajrud protected area and its neighbouring protected areas including varjin, lar, koohsefid and the surroundings. Regarding to seasonal variation of the species home range, winter, summer and multi seasonal (annual) habitats were predicted. To estimate habitat connectivity, we used models of connectivity based in electrical circuit theory. Applying core areas of multi season for connectivity analysis, movement pattern of the species was predicted and important connective areas for conservation were identified. Species distribution maps revealed that the summer and winter habitats were approximately occurred in similar areas. Distance to eco-guards' post was the most important predictor for both habitat models of summer and winter. The annual model, which is a combination of summer and winter, shows that the largest suitable habitat patches are located in the north, south and west of the study area. Maximum current flow map demonstrates that the areas among patch pairs are covered in low current, reflecting low rates of the species dispersal. This map presented bottlenecks to the species movement across major roads and along extending human settlements. Cumulative current flow map displayed that current was highest in Jajrud north of Mamloo extending to the northern Jajrud. Overall, our study demonstrated a prediction of habitat suitability and connectivity for Alborz wild sheep in east of Tehran, which can be used to direct conservation endeavours dealing with maintenance of the wild sheep metapopulation dynamics.

*Corresponding author. 


\section{Keywords}

\section{Habitat Connectivity, Alborz Wild Sheep, Electrical Circuit Theory, MaxEnt Modeling}

\section{Introduction}

Landscape alteration by anthropogenic activities is the most important cause of habitat loss and fragmentation, which in turn, results in loss of biodiversity worldwide [1]. New conservation efforts consider connectivity as one of the best responses to offset negative effects of habitat loss and fragmentation on biodiversity [2]. Thus, conservation authorities need to identify and prioritize among places that are important for maintaining and restoring connectivity.

At the global scale, many of the biological conservation schemes have been focused on the patterns of threatened species' occurrence for identifying areas important for the long-term preservation of biodiversity. The rationale behind this particular attention is the excessive risk of threatened species loss in the near future and thus the need of urgent conservation action for their persistence [3]. Protecting and recovering threatened species necessitates not only the protection of main habitat patches, but also enough management of linkages that facilitate movement between them [4]. It is expected that, threatened species suffer from continued habitat fragmentation, severely. Since, the time from fragmentation to species extinction would be lesser. Therefore, we have low opportunity to employ connectivity preservation and restoration practices that may rescue these species that otherwise would have been in a trajectory toward extinction. Thus, reliable methods and techniques that can predict the species' distribution and estimate connectedness of their habitats are needed.

Alborz wild sheep (Ovis Orientalis Gmelini $\times$ Ovis Orientalis Arkal), recorded in IUCN red list of threatened species, is distributed in relatively low populations in most of the protected areas of Tehran province (including Jajrud, Varjin, Lar, Koohsefid, and so forth). During the last four decades, human population of the province doubled while the associated built area expanded by the four times. These events have accompanied by sprawl spread of human settlements, enlargement of road ways and development of other infrastructures, which might have caused wildlife and their habitats to be dramatically affected. Amongst, wild sheep populations have become fragmented and their movements appeared to be limited [5]. In this context, persistence of the wild sheep populations is logically relied on preservation and restoration (if possible) of connections among isolated habitat patches.

We demonstrated applying an approach for modeling habitat suitability and connectivity of the wild sheep in the eastern area of Tehran province. We modeled Alborz wild sheep, since they are internationally categorized as threatened under the latest update of the IUCN red list [6] and also nationally classified as protected species according to approval No. 168 (1999) under the Game and Fish Act (1967) of Iran [7]. Across the east of Tehran province, their habitats have becoming fragmented under continued pressure of urban growth and other forms of anthropogenic development, such as transportation networks, energy transmission lines, water supply systems, and military infrastructures [8].

Our objectives were to: 1) identify the variables most likely to influence the wild sheep presence; 2) build model of habitat suitability and identify key patch places; 3 ) determine areas important for maintaining habitat connectivity for the wild sheep. Importantly, we aimed to test application of new classes of connectivity models rooted in electrical circuit theory to connectivity conservation of the wild sheep or other species of our country. Indeed, we wanted to test its functionality in our country where we usually face with lack of data, documented knowledge of the species behavior and scientific efforts in quantifying the influence of human dominated landscapes' features on the species' movements.

\section{Material and Method}

\subsection{Study Area}

We modeled Alborz wild sheep habitat suitability and connectivity in eastern part of the province of Tehran extending to the two neighboring provinces of Mazandaran and Semnan (Figure 1). The study area with a longitude of $51.50^{\circ}$ to $52.57^{\circ}$ and latitude of $35.24^{\circ}$ to $36.06^{\circ}$ is approximately $4957 \mathrm{~km}^{2}$ and encompasses a network 


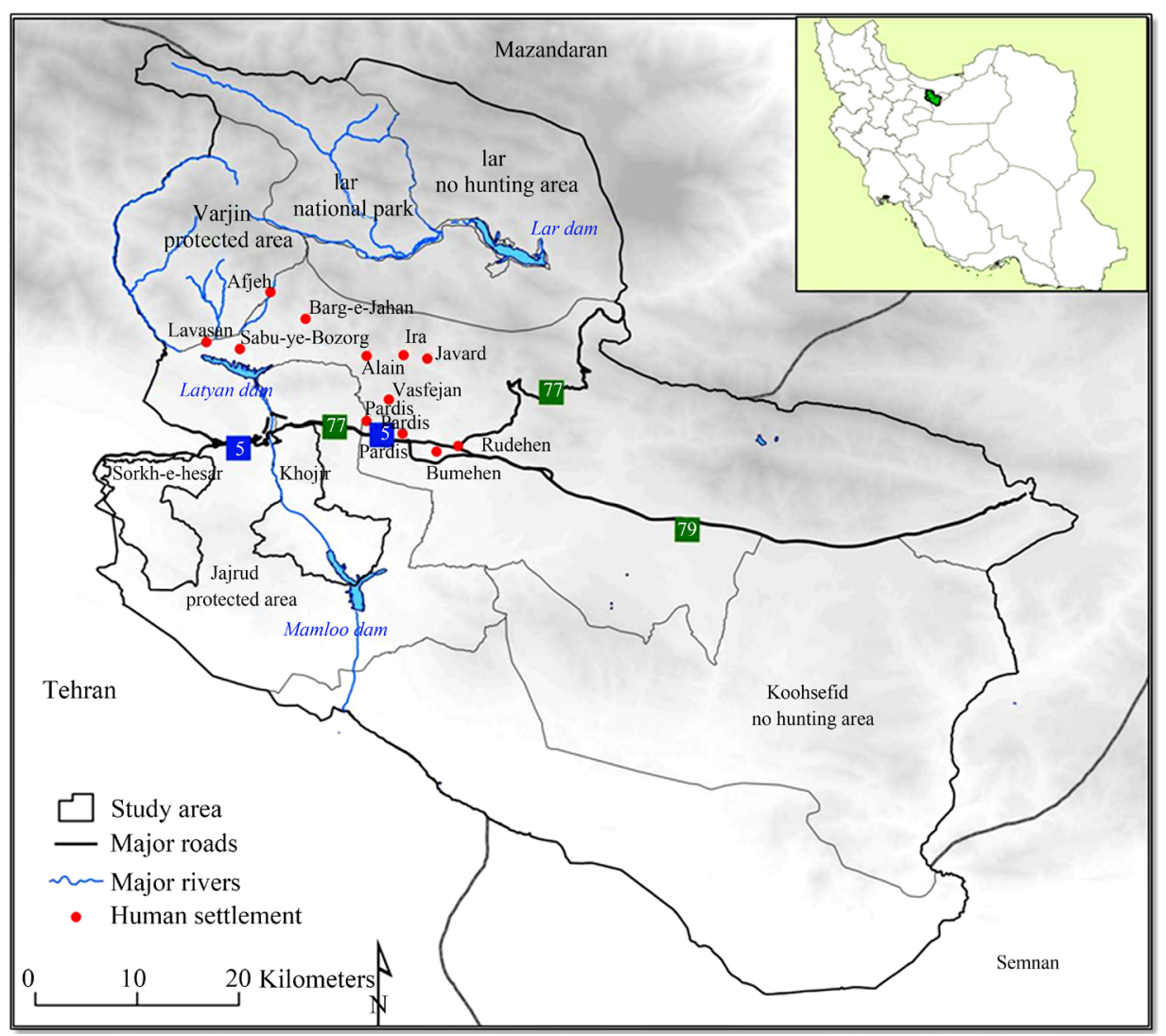

Figure 1. An overview of the study area.

of protected areas, including jajrud, varjin, Lar and koohsefid. Network of the protected areas was chosen due to: 1) historical contribution of the network to dispersal and gen flow of wildlife populations, including our study species and 2) threats to conservation of wild sheep, imposed by human population growth and infrastructure development in this region.

Jajrud protected area, encloses Sorkh-e-hesar and Khojir national parks, is located on the southern slopes of Alborz Mountain close to Tehran. The extremely high biodiversity of the area is its special feature. Closeness of the region to Tehran has also raised significance of the area [9]. Varjin protected area, on the north of Jajrud, is placed on the southern slopes of Alborz Mountain nearby Tehran. In addition to high plant and animal diversity, its performance as a corridor for the animals-especially wild sheep-between Central Alborz and Lar, is the unique feature of the area [9]. Lar (comprising the national park and no a hunt area) is located in the north of Jajrud and west of mount Damavand. Lar is summer habitat for a large number of wildlife species, especially for wild sheep [9]. Koohsefid is a no hunt area in east of Jajrud. The area is home to great number of animal species, like wild sheep, wild goat, wolf and etc.

Due to being close to Tehran metropolitan, our study area has been severely affected by built environment development especially by expansion of roads and human settlements. For e.g. construction of Pardis new city which is expanding into Jujrud protected area, growth of other cities and villages (i.e. Lavasan, Sabu-ye-bozorg, Rudehen and Bumehen), development of new roads such as 4-lane pardis freeway in parallel to Damavand road that both are crossing through Jajrud protected area, and also building of Latyan, Lar and recently Mamloo dams, have collectively imposed barriers to wildlife migration corridors.

\subsection{Study Species}

Alborz (red) wild sheep is a hybrid of the Armenian mouflon (O. o. gmelini) in the west and transcaspian Urial (O. o. arkal) in the east of Iran [10]. This species is listed as Vulnerable by IUCN because it is perceived to be decreasing due to hunting, hybridization and habitat degradation. They naturally occur in the Alborz Mountains 
of north-central Iran close to Tehran, east to the Parvar Wildlife Reserve and south into the Kavir Desert (Siah Kuh range). Drawing definite lines between the Urial on one side, the Armenian on the other and the wild Alborz in between is impossible; thus, the exact eastern, western and southern boundaries of distribution of the sheep are undetermined [6] [10]. Now, most of the Alborz wild sheep populations are present in Sorkh-e-hesr, Khojir and Varjin. They used to migrate from Lar and Varjin to Sorkh-e-hesr and Khojir and vice versa. Nowadays their migration hardly takes place, due to construction of roads, dams and also development of human settlements [11].

\subsection{Methods}

We assessed habitat suitability at the whole of study area, during summer and winter and at the same time for the both sex of male and female. Our choice of analysis scales was based on our goal of determining areas important for maintaining landscape connectivity across the study area. We were interested in understanding how connectivity is affected by landscape elements in Jajrud wherein despite the inconsistency with its primary goal of protection and high environmental value, broad areas have been occupied and construction activities are being done. Assuming that movement of the study species across Jujrud is extended into neighboring natural areas, we expanded our study area beyond Jajrud and covered adjacent protected areas, including Varjin, Lar and Koohsefid. Since landscape features affecting connectivity would not be likely managed seasonally, we derived a single multi season model to identify important habitat patches and movement corridors. We were also looking for identifying habitat patches and connections that potentially would be used by the both male and female because both are involving fragmentation.

Maximum entropy (MaxEnt) modeling was used to determine areas of higher suitability habitat, which is known core habitat areas. While modeling species distribution, alterations in habitat use caused by seasonal changes throughout the annual cycle were taken into consideration. In order to develop a multi season (annual) model, summer and winter habitat selection models were combined. To assess habitat connectivity, we used core areas in modeling of connectivity based in electrical circuit theory. Applying core areas as focal regions for connectivity analysis, movement pattern of the study species was predicted and therefore important connective elements for conservation were identified.

\subsubsection{Occurrence Data}

We collected 425 points of the species location at the entire of study area which 235 of them is related to winter and the other 190 is based on summer presence. These distribution data come from three sources: 1) our field observations throughout the species' range in Jajrud using GPS and map-based interviews with conservation officers of the protected area during the June 2015-February 2016, 2) recent census data of the study species in Varjin [12] and Koohsefid [13], throughout 2014, recorded by Tehran provincial directorate of environmental protection (Tehran DOE), 3) occurrence data of the species in Lar, around 2013-2014, recorded by Mashhadi Ahmadi in the course of doing his research on corridor modeling for Alborz wild sheep in Tehran province [5] and also map-based interviews with conservation officers of Lar for confirmation and modification of the data if they felt necessary.

\subsubsection{Environmental Data}

We considered 14 environmental variables in the variable selection procedure (Table 1) and used a GIS [14] to compile the variables' maps from multiple data layers. The environmental variables fall into two broad categories of ecological factors and anthropogenic features. Ecological factors included digital elevation model (DEM), vector ruggedness measure (VRM), vegetation density including eight range types favoured by the species and proximity to springs. Anthropogenic features contained road density, building density and closeness to eco guards' posts. Many of these or the same variables have been notified in the literature as important parameters affecting the species habitat suitability and movement. Examples including variables such as elevation, slope, aspect, standard deviation of slope [5] [15], escape terrain [15], ecological and built area variables such as distance to roads, urban and village areas [5] [15], and water bodies [5].

\subsubsection{Ecological Factors}

DEM of study area was created using national DEM prepared by National Cartographic Center (NCC) of Iran 
Table 1. Set of the environmental variables used.

\begin{tabular}{cccc}
\hline Category & Variable & Code & Source \\
\hline & digital elevation model $(\mathrm{m})$ & DEM & NCC \\
vector ruggedness measure $(\mathrm{m})$ & VRM & Calculated from NCC DEM \\
& Artemisia aucheri-acantholimon & Art_auc_aca & RIFR \\
& Stipa scariola & Sti_sca & RIFR \\
Ectemisia siberi-stipa & Art_sib_sti & RIFR \\
& Astragalus onobrychis & Psa_ono & RIFR \\
& Psathyrostachys-agropyrun & RIFR \\
& Perennial grasses-thymus & RIFR \\
Ferula-Psathyrostachys & Fer_psa & RIFR \\
Anthragalus-Stipa & Ast_sti & RIFR \\
& Distance to springs (m) & Spring_dis & NCC \\
& road density & Road_dns & NCC \\
\hline
\end{tabular}

[16], dataset of the study area boundary and extraction function of Arc GIS. DEM layer's extent was imported as reference for all other variables. We used DEM and the spatial analyst extension of Arc GIS to measure terrain ruggedness (in meters).We derived vegetation (range cover) types of our study area from spatial data on "ecological regions of Iran: vegetation types of Tehran area” generated by research institute of forests and rangelands (RIFR) of Iran [17]. To determine which types of range cover should be included in our analysis, preferred range types by the species identified using intersection of the species occurrence shape file and the spatial data on range types of the area. Then, we measured mean of the selected range types' values in the rectangle neighbourhood with height and width of $1500 \mathrm{~m}$ by using neighbourhood statistics function of Arc GIS. Distance to springs (in meters) was computed using spring shape files developed by NCC [18] and Euclidean distance calculation function in Arc GIS.

\subsubsection{Anthropogenic Features}

The density of all road types (1000 m radius) and Building blocks (rectangle neighbourhood $1500 \times 1500 \mathrm{~m}$ ) were calculated using kernel density and neighbourhood statistics functions in Arc GIS, respectively. In both cases, data were obtained from NCC's shape files [18] which we updated by digitizing new features from Google earth. We measured distance to eco-guards' posts (in meters) using their geographic coordinates and the Euclidean distance calculation function in Arc GIS.

Entering highly correlated variables in MaxEnt model, limits interpretation of the contribution of correlated variables. This is primarily because when a model is built in MaxEnt, if a highly correlated variable is included in the model, this often excludes all other highly correlated variables from being integrated [19]. Correlations of environmental data were checked in Minitab software [20] by carrying out Pearson's correlation analysis. Since variables showed little correlation, all the 14 variables were contributed in building the MaxEnt model.

\subsubsection{Habitat Modeling}

To identify geographic distribution of the investigated species, we used MaxEnt modeling which is a machine learning method with an easy and accurate mathematical formulation. It requires only presence data together with environmental information for the entire study area. MaxEnt estimates species' distributions by finding the distribution of maximum entropy, subject to a set of constraints that the expected value of each environmental variable under estimated distribution matches its empirical average. When MaxEnt is applied in species distribution modeling, each grid cell of the study area presents a probability species distribution, which may be interpreted as an index of habitat suitability for the species [21].

To map the potential habitat of the species, the total of 14 environmental layers were projected to the UTM 
zone $39 \mathrm{~N}$ to match their coordinates, extracted to the extent of DEM, converted to ASCII format and together with the CSV file of the species presence locations entered into MaxEnt software [22]. For both summer and winter habitat models run in this study, $75 \%$ of the species records selected to train the model and $25 \%$ of the remaining reserved for testing the created MaxEnt distribution model, feature type was set to "auto feature”, the output grid format as "logistic", and all other parameters at their default settings. To identify how each variable affects the MaxEnt prediction, response curves were created and to measure variable importance, environmental variables were jackknifed. To evaluate our models we used receiver operating characteristic (ROC) analysis, which characterizes the performance of the model by the area under the ROC curve (AUC) of training and test data. To characterize core areas, we applied "maximum training sensitivity plus specificity" threshold to the MaxEnt model logistic values and selected polygons $>5 \mathrm{~km}^{2}$ and $>10 \mathrm{~km}^{2}$ for winter and summer respectively. Thresholds for core areas were barrowed from the species seasonal home ranges. Based on the experts' opinion, an area of about $10 \mathrm{~km}^{2}$ is essential to maintain a summer population of 20 animals and the winter range of the study species herd with 20 animals is around $5 \mathrm{~km}^{2}$. Lastly, the resulting map of high suitability summer and winter habitat patches was sent to experts for review and modification if they thought necessary.

We then developed an annual habitat model by combining habitat models of summer and winter. To integrate separate seasonal models in an ecologically meaningful way, intersection of both models of the seasons was computed using overlay toolset in Arc GIS. Applying union function allowed us to enter the whole extent of core habitat areas of the both summer and winter in the annual model. It is important because omission of one or a part of each seasonal core habitat areas in the process of establishing the annual model may lead to misunderstanding of connectivity which affects the identification of conservation and restoration priorities.

\subsubsection{Connectivity Modeling}

To predict connectivity across the annual model, we employed concepts from circuit theory using Circuitscape software [23]. This requires focal nodes files representing points or regions between which connectivity are to be modeled and habitat maps reflecting permeability of each cell in the landscape to flow current. Circuitscape translates spatial data set into a graph structure converting cells to nodes and connecting them to their immediate neighbours by resistors. This produces maps that show the current density at each cell in the landscape showing the load of current flowing through the node. Current map used to represent important connectivity areas between core areas of habitat patches. Higher densities of current between habitat patches reveal spaces by which individuals are more likely to move. Greater connectivity among habitat patches is predicted when multiple pathways are available. Locations where current densities are high or where alternative pathways are not available show pinch points that act as bottlenecks to movement. They reflect conservation priorities because their loss has high impact on connectivity [24].

Our use of circuit theory in analysing connectivity involved applying current flow among core areas of habitat patches to determine important areas for conserving connectivity both for movements among habitat patch pairs and for maintaining connectivity across the entire network of habitat patches in the study area. To generate current maps, circuitscape was operated in the pairwise mode using the core areas and conductance layers created from previous habitat modeling on maxEnt. Under running circuitscape in the pairwise mode, we checked writing maximum of current map. The maximum of current map determines areas with higher densities of current between patch pairs whereby successful dispersers are more likely to move [25]. This identifies bottlenecks to movement, where no alternative pathway is available, so called pinch points. To analyse connectivity across the entire network of habitat patches, we calculated current flow between all pairs of habitat patches to produce a map of cumulative current flow among all available pairs. Modeling cumulative current flow provides a means of analysing the importance of both patches and intervening areas for maintaining connectivity of the entire network of habitat patches. To precisely measure how important a core area is for keeping the network connected, we used Centrality Mapper [26] that allowed us calculating current flow centrality across the network in the landscape of our study area.

\section{Results}

\subsection{Habitat Modeling}

The main results of habitat modeling include habitat suitability maps, analysis of importance of variables along with response curves to environmental variables and ultimately evaluation of model performance. 


\subsubsection{Habitat Suitability Maps}

Our models and anticipating maps of the species distribution identified 6 summer and 10 winter habitat patches (Figure 2). Totally, $16.22 \%$ of the study area accommodated potential summer and $10.87 \%$ potential winter habitat. Summer and winter habitat appeared in similar areas, but winter habitat was more restricted.
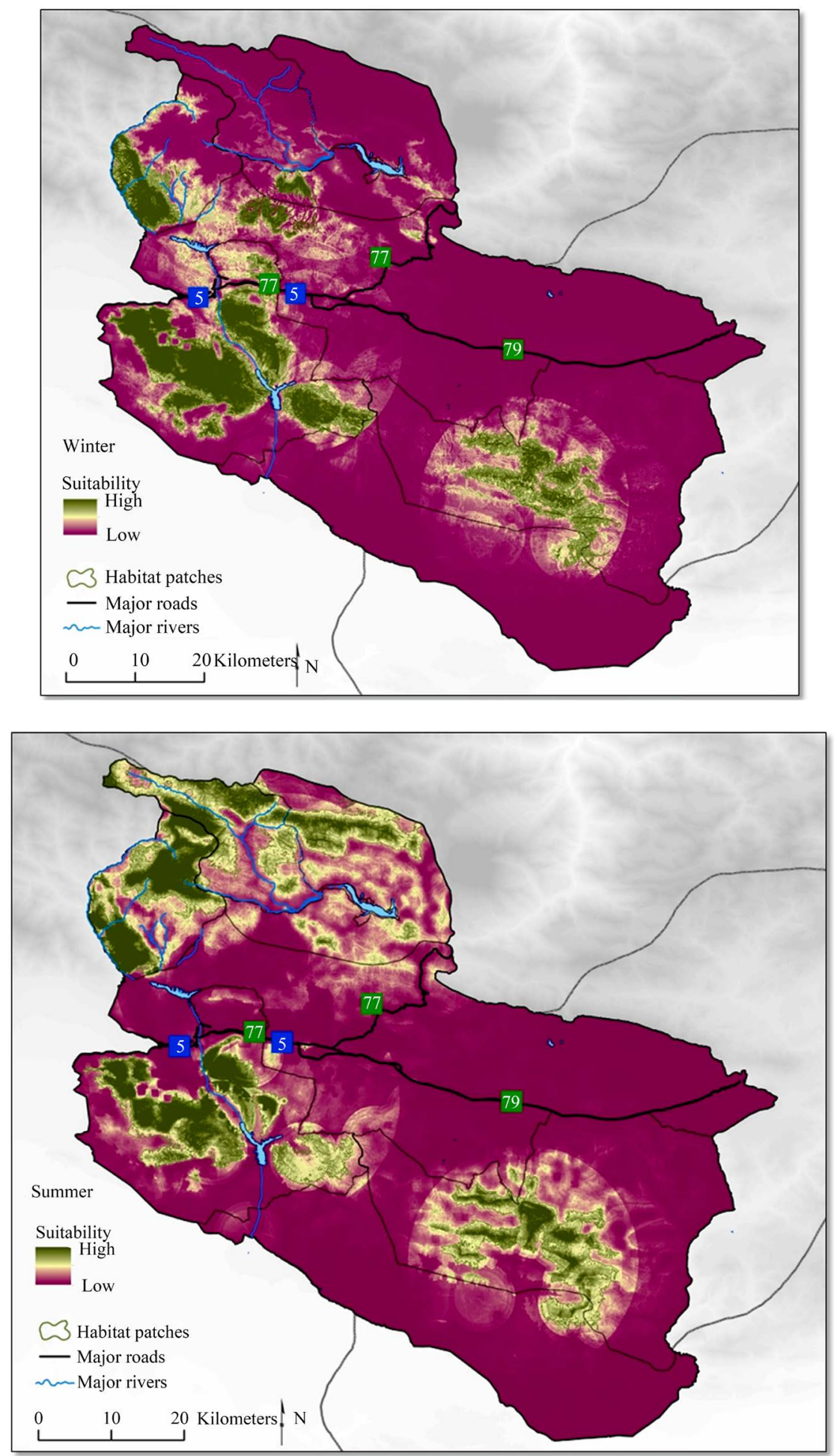

Figure 2. Habitat suitability maps for winter (top) \& summer (bottom). 
The annual model, which is mixed of summer and winter models, showed that north, south and west of the study area comprised large areas of suitable habitat in our predictions (Figure 3). Central and Eastern part of the study area had only low suitability. In general, suitable habitat was primarily discovered within the protected areas especially in jajrud and varjin and was relatively scarce in Lar and koohsefid.

\subsubsection{Variable Importance and Response Curves}

Model variable importance analysis showed that "Distance to eco-guard' posts" was the most important environmental predictor for both summer and winter, accounting for $36.2 \%$ and $34.1 \%$ gain contribution in summer and winter, respectively. The next important predictors were "distance to springs" followed by "DEM" for summer and "vegetation density (stipa scariola)" and "DEM" for winter.

The response curves associated with the most influential factor showed that both of winter and summer habitat suitability was highest around eco-guard posts while declining at higher values (Figure 4(a) and Figure 4(b)). Higher probability of summer occurrence was predicted at lower values of Spring_dis. First, it started with a gradual decline at $2000 \mathrm{~m}$, then fell steeply tree times (at $4000 \mathrm{~m}, 4500 \mathrm{~m}$ and around $5000 \mathrm{~m}$ ) and at the end decreased slightly with increasing values of spring_dis (Figure 4(c)). The response curve for "stipa scariola" showed positive relationship with winter habitat suitability of the species. As Figure 4(d) shows, first, the species probability started with a jump and then continued to a slow rise with increasing values of sti_sca. The summer response curve for "DEM" depicted highly suitable summering areas in elevation of about $3800 \mathrm{~m}$ (Figure 4(e)); while the different pattern of the winter response of the species to DEM, reflected its affinity towards areas with lower elevation in winters (Figure 4(f)).

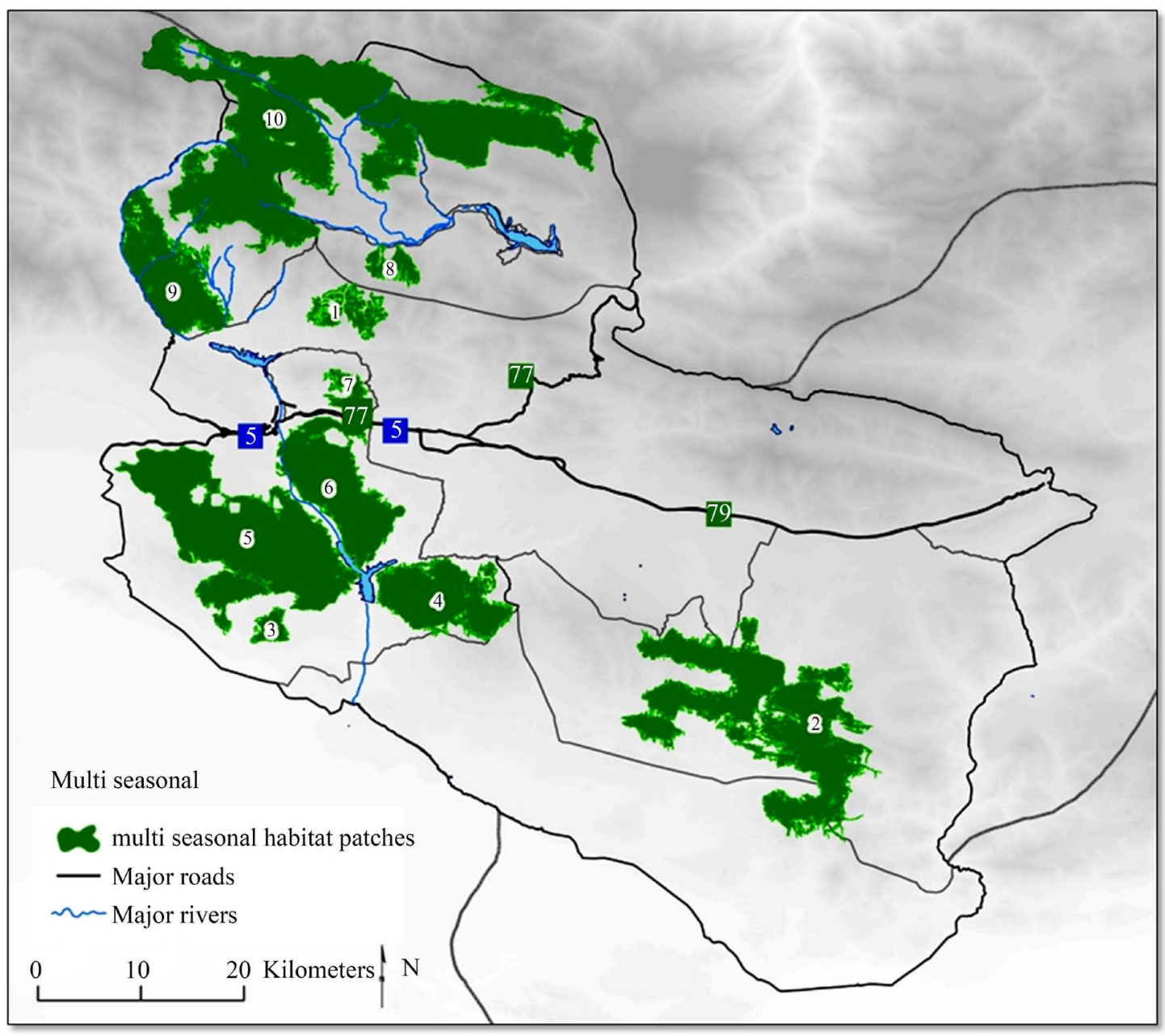

Figure 3. The multi seasonal habitat map. The green polygons view potential habitat over annual cycle. 

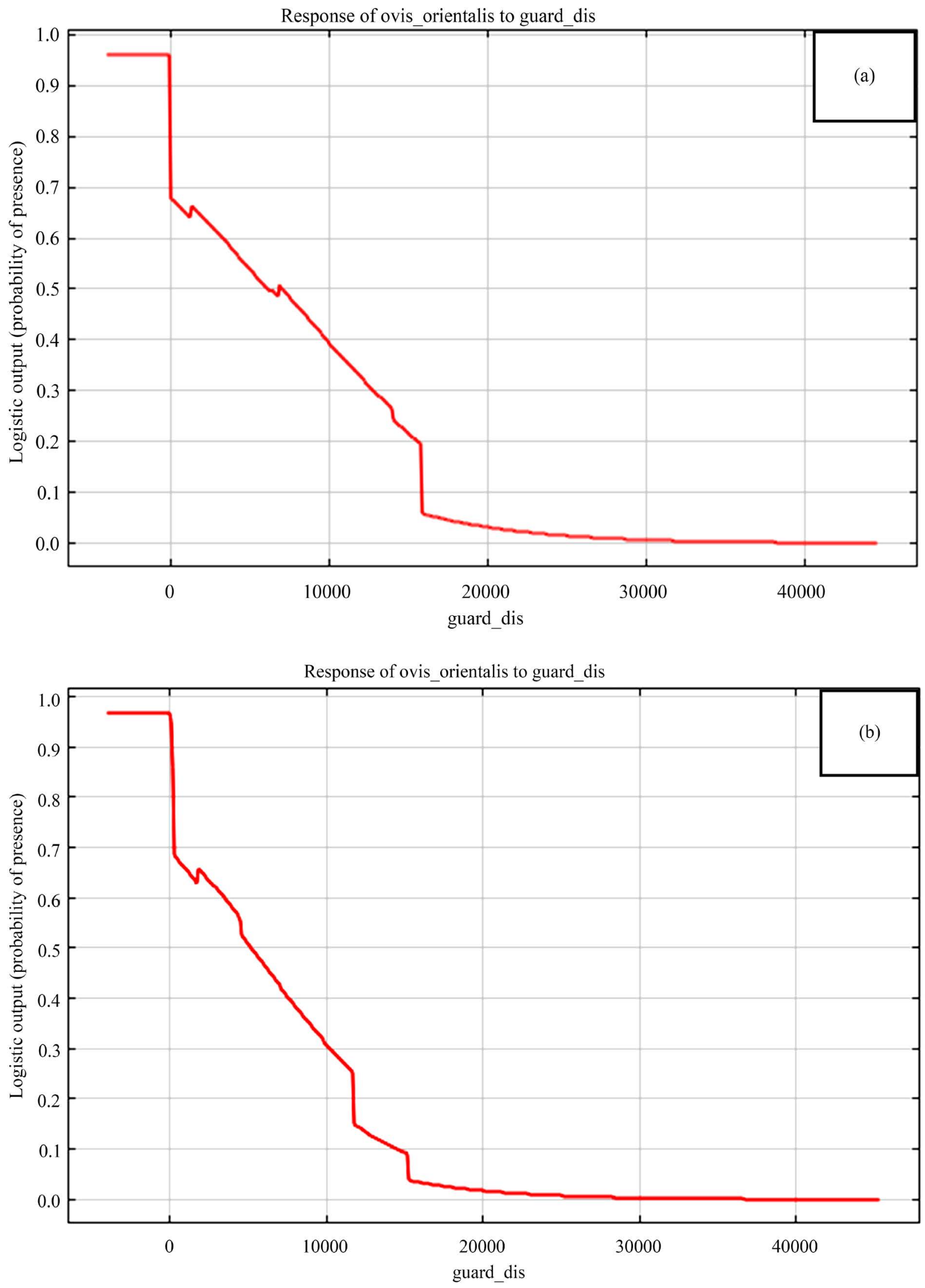

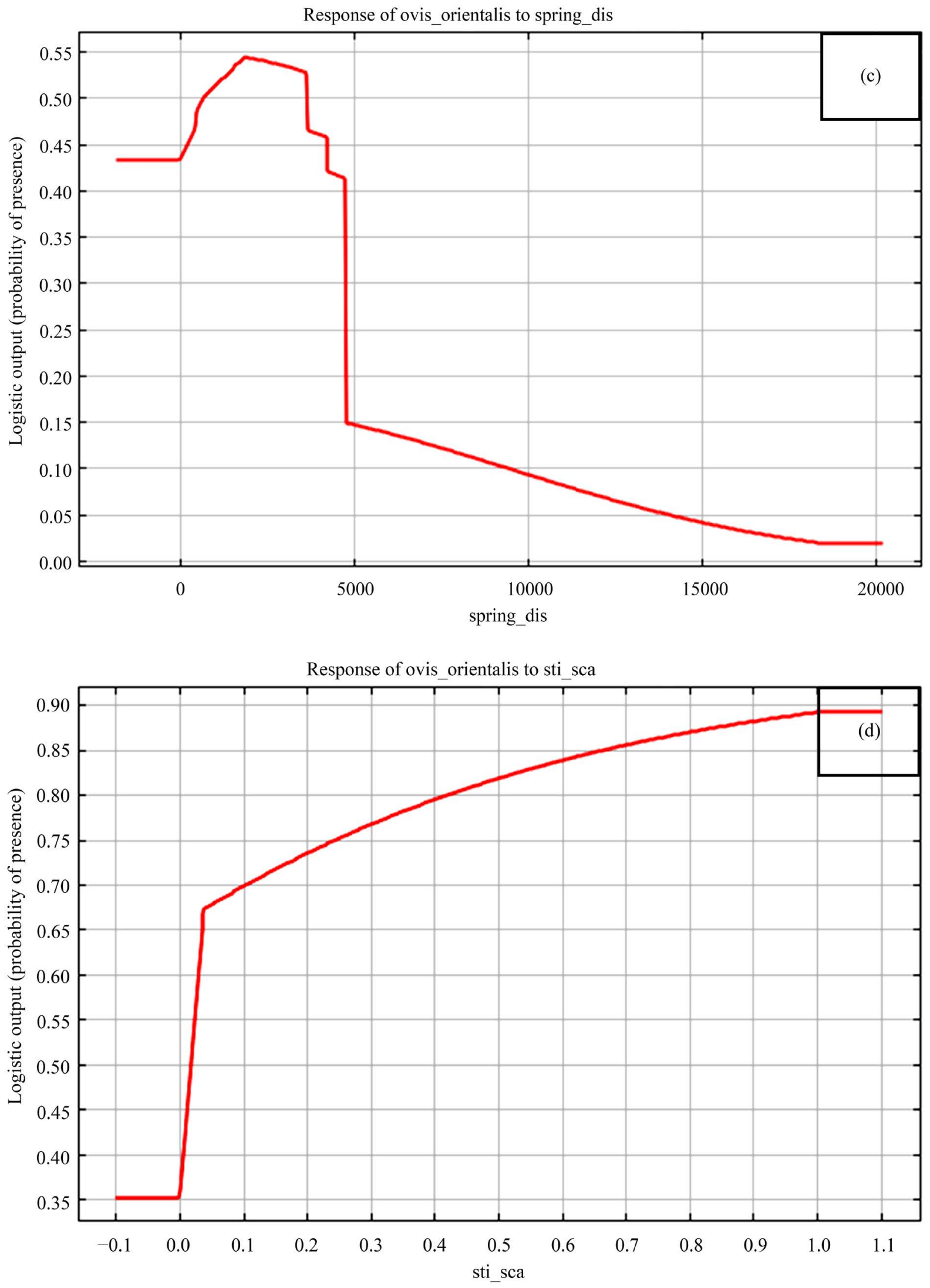

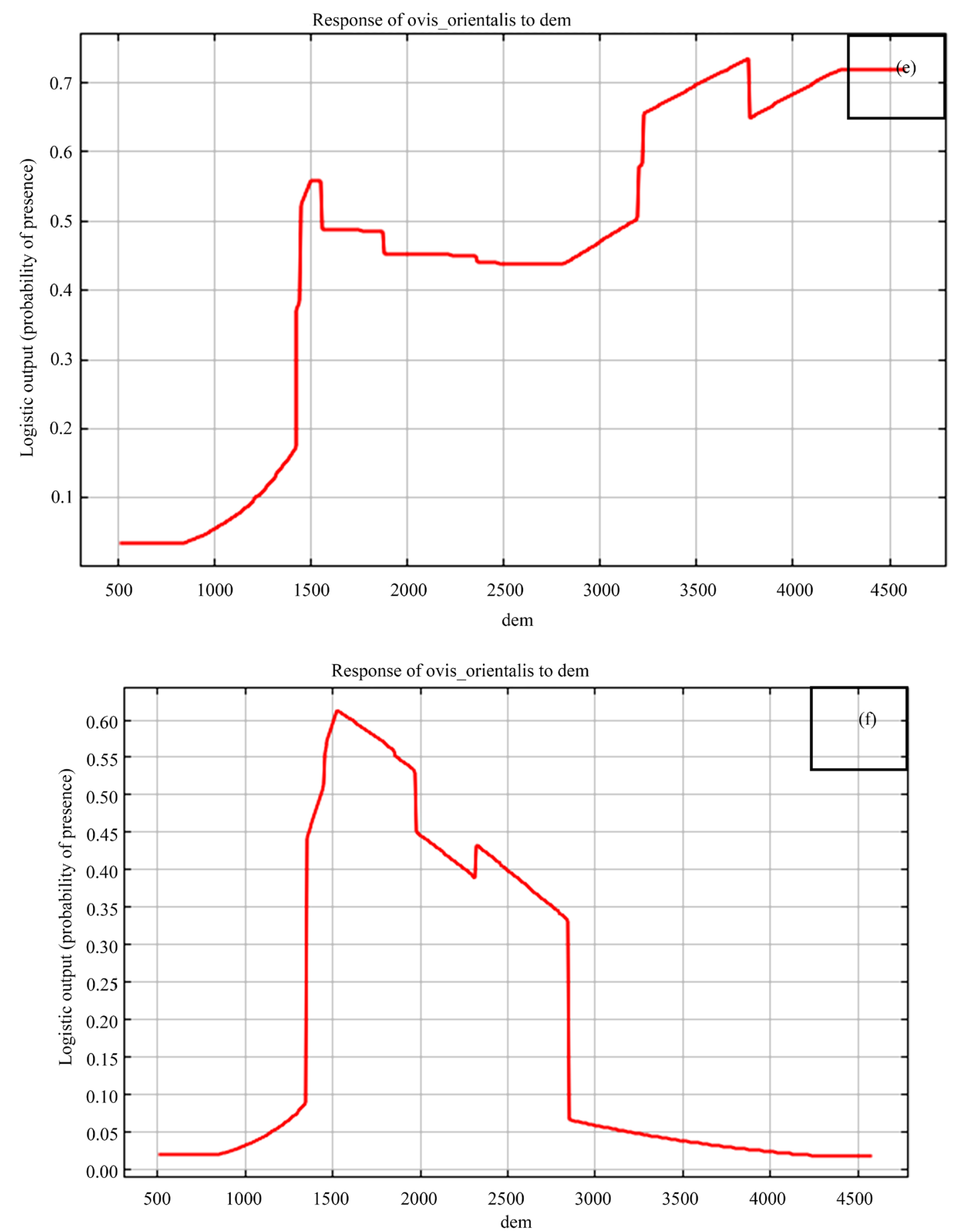

Figure 4. Response curves for the most significant variables of summer and winter habitat suitability according to Maxent model. Environmental variable codes: in figure (a) and (b), gauard_dis = distance to eco-guards' post; (c) spring_dis = distance to springs; (d) Sti_sca = Stipa scariola; (e) and (f) DEM = digital elevation model.

\subsubsection{Model Evaluation}

For both models of summer and winter, the area under the curve (AUC) of the receiver operating characteristic (ROC) plots were high for the training data (AUC > 0.90) and test data (AUC > 0.85) (Figure 5(a) and Figure 5(b)). Both measurements show that the both model performed good, and suggest that models' predictions are accurate to represent the species distribution. 


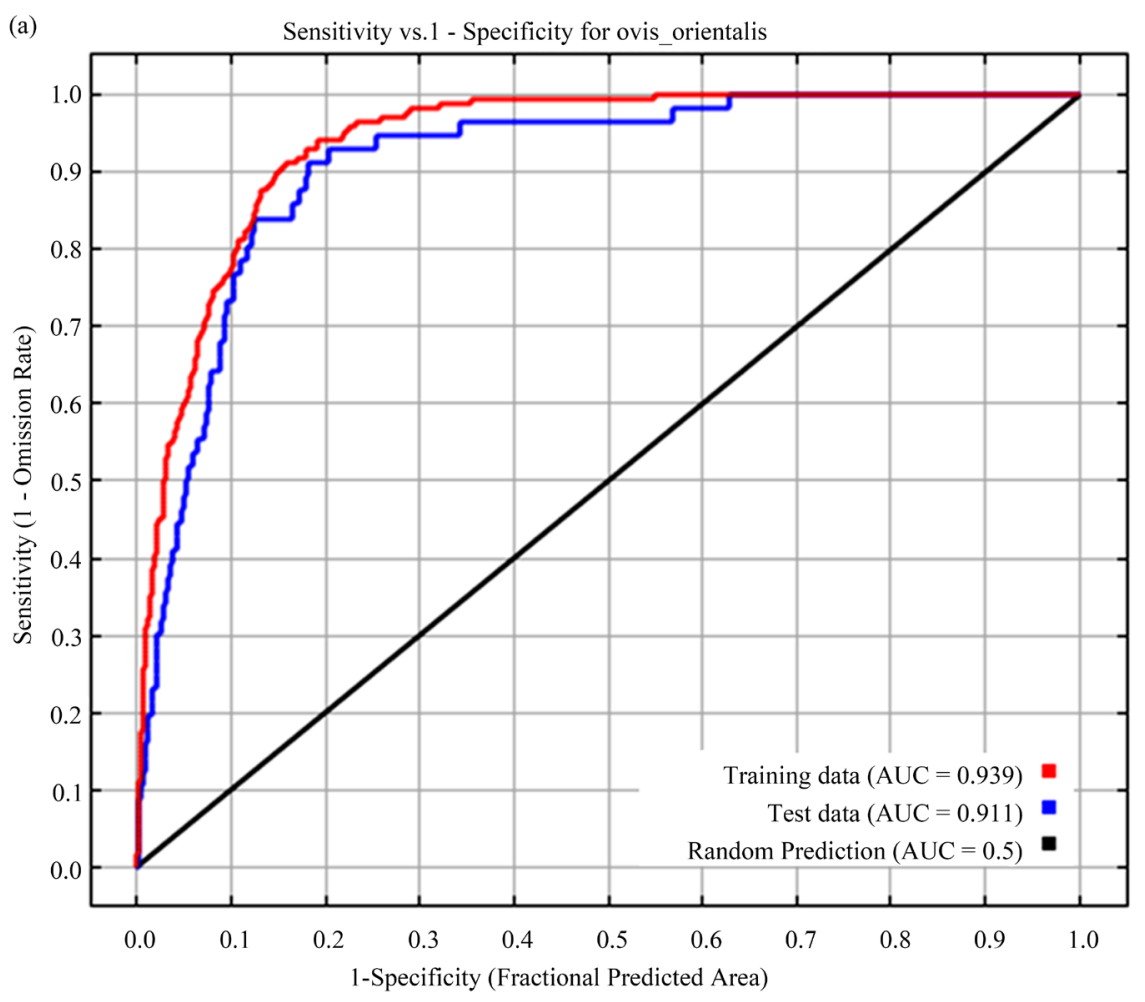

(b) Sensitivity vs.1 - Specificity for ovis_orientalis

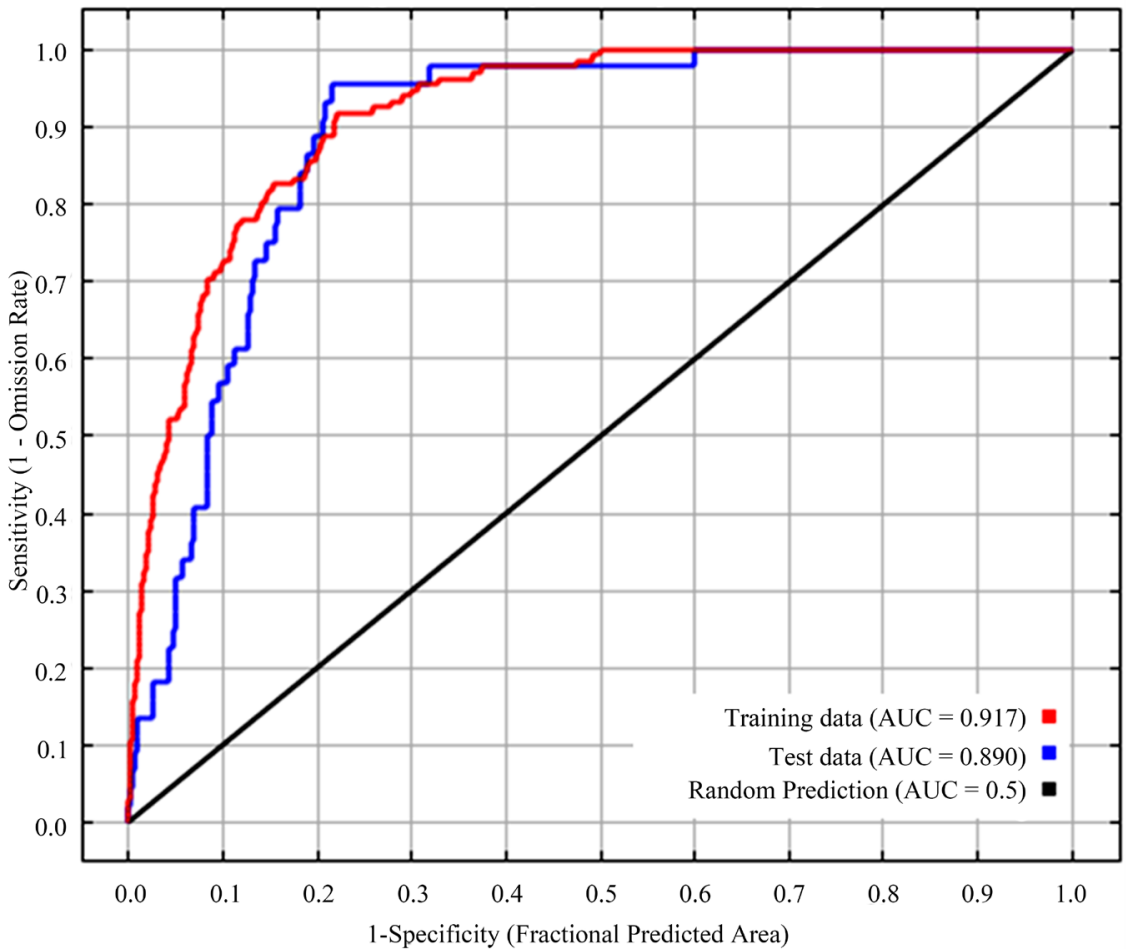

Figure 5. ROC curves of sensitivity vs. 1-specificity for our study species based on results obtained from Maxent models. ROC curves of winter (a) \& summer (b) modeling is shown separately. The black curves with an AUC value of 0.5 indicate random prediction, while the other curves in blue and red with values closer to 1.0 indicate performance of the models. 


\subsection{Habitat Connectivity}

The map of maximum current flow demonstrated the currents entered at each pixel (Figure 6). What is evident on this current map is that the areas between patch pairs are generally covered in low current flow. This map identified possible pinch points for connectivity of the species movement between patch pairs. Pinch points were found: for e.g. across the 5 (Tehran-Pardis Freeway) and 77 (Damavand road) transportation corridors, between patches 6 and 7; around the artificial lake behind the Mamloo dam, between patches 6 and 4 and also 6 and 5; along the route from Barg-e-Jahan to Afjeh, between patches 1 and 10; along the surface between Ira and Alain from one side and Javard and Vasfejan from the other side, among patches 8 and 7.

The map of cumulative current flow displays the sum of currents when all patch pairs were iteratively connected (Figure 7). This map draws attention to the areas important for maintaining the entire network connected. Cumulative current flow was highest in Jajrud north of Mamloo (patch 6) extending towards northern Jajrud (patch 7). Also, current flow was relatively high across south eastern corner of Jajrud (patch 4) and from east of Sorkh-e-hesar to the west of Mamloo (patch 5). In general, the pattern of high current was in crescent shape which flew along the northern, western and southern boundary of the study area. This is because no habitat patches were modelled in the east of under study area.

Running Centrality Mapper indicated current core flow centrality scores (Table 2). This clearly showed that the patch number 6 was the most significant core area for maintaining the overall connectivity in the network. If this patch that has the highest centrality score is lost or converted, it would most greatly decrease the overall network connectivity.

\section{Discussion}

Our models and maps demonstrated an estimate of habitat suitability and connectivity for Alborz wild sheep in

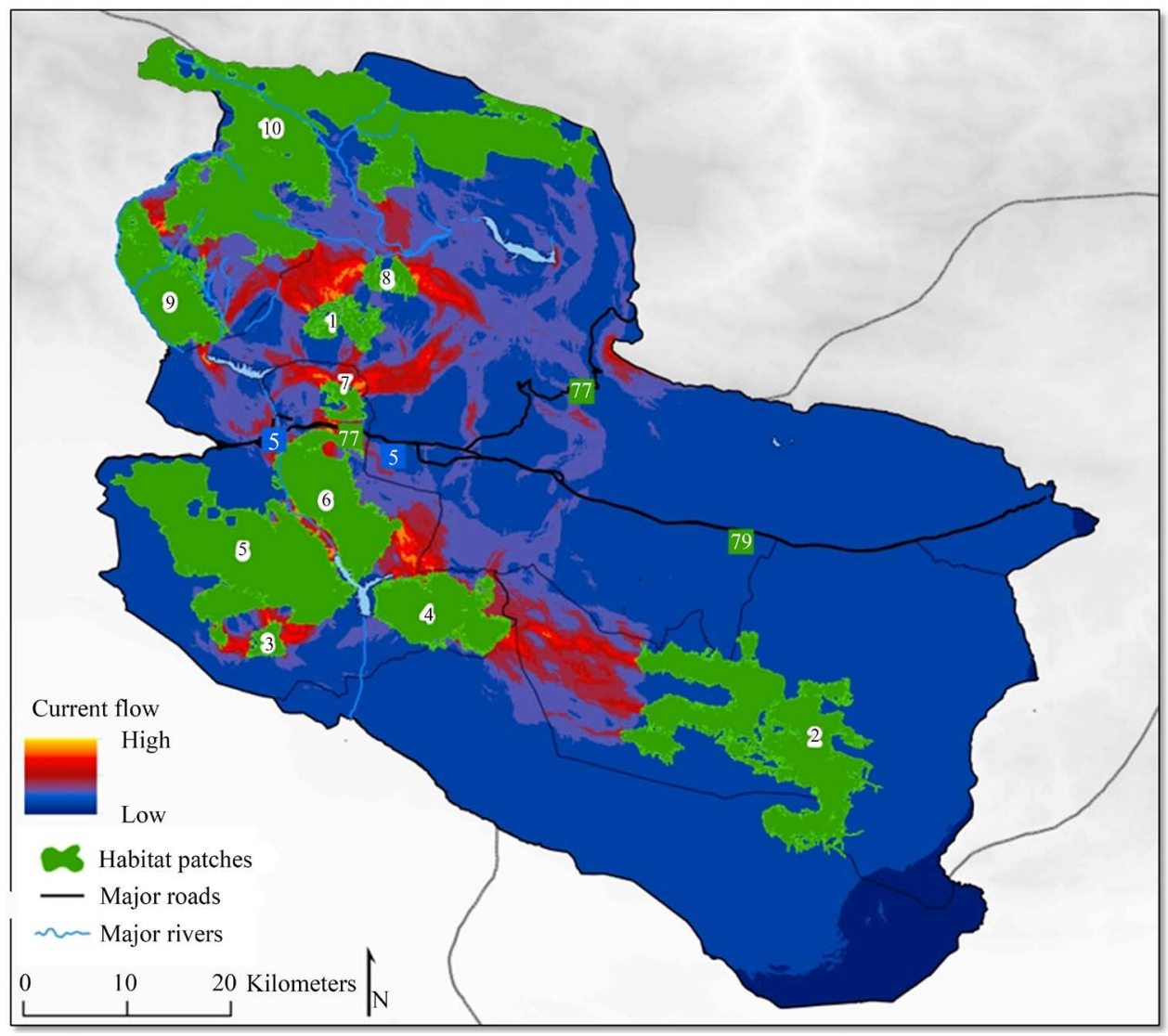

Figure 6. Model of maximum current flow. The map was displayed using Quantile classification method. Habitat patches are uniquely numbered for reference. 


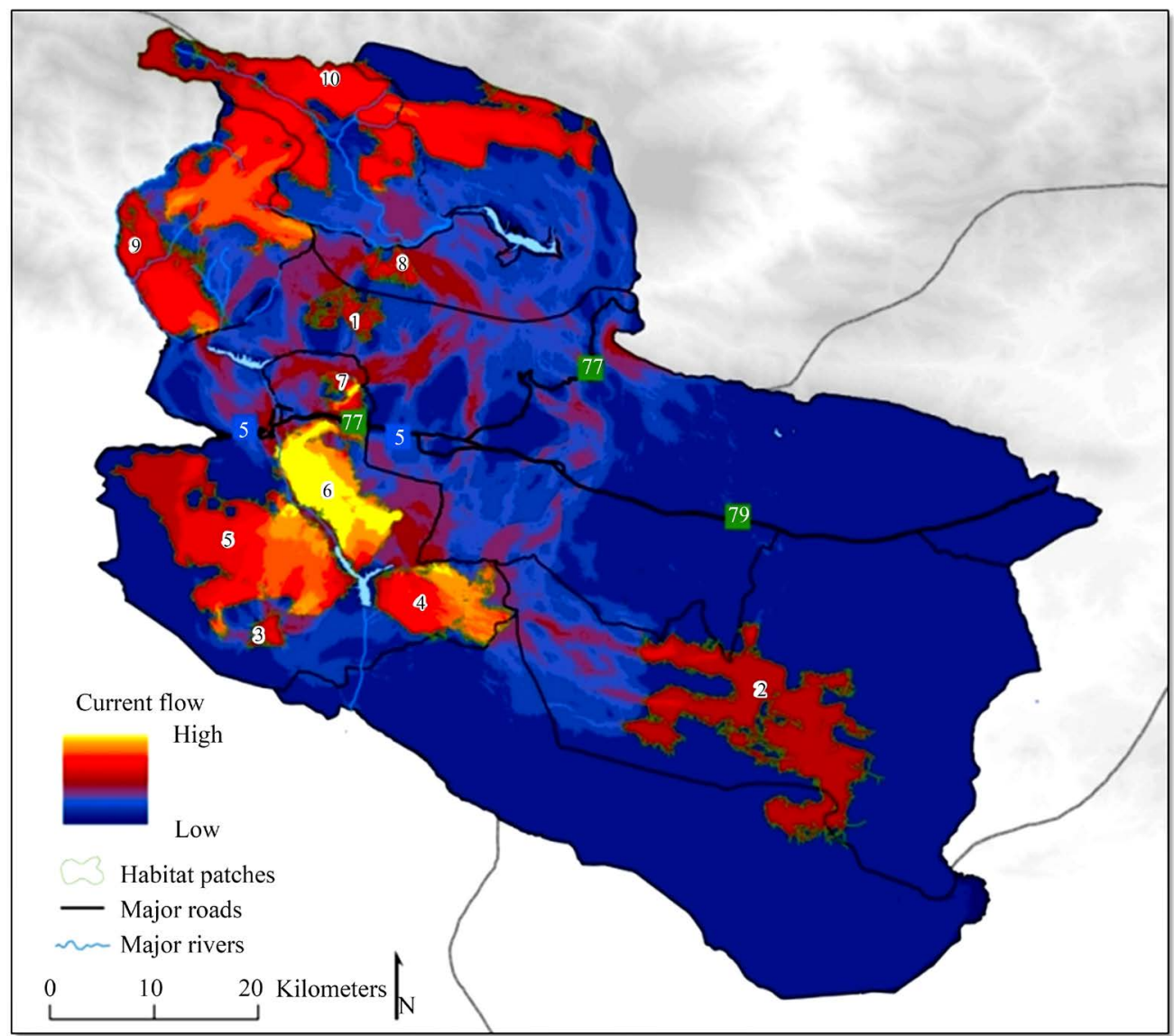

Figure 7. Model of cumulative current flow. The map was displayed using quantile classification method. Habitat patches are uniquely numbered for reference.

Table 2. Current core flow centrality scores.

\begin{tabular}{cccc}
\hline & Current flow centrality score & \multicolumn{1}{c}{ Current flow centrality score } \\
\hline Patch 6 & 31.06 & Patch 10 & 15.62 \\
Patch 7 & 29.84 & Patch 9 & 15.41 \\
Patch 1 & 22.51 & Patch 8 & 12.6 \\
Patch 5 & 22.07 & Patch 2 & 9 \\
Patch 4 & 17.76 & Patch 3 & 9 \\
\hline
\end{tabular}

the east of Tehran province; within Jajrud protected area, counted as one of the best habitat for our study species [11], and its interrelated neighboring protected areas including Varjin, Lar and Koohsefid and the spaces between. Our evaluation of habitat suitability showed that key habitat patches are in areas around the eco-guard' posts and water bodies, distant from built environment, of rolling lands and rugged terrain and rangelands dominated by grasses and non woody plants. These findings were not unanticipated, since they had been similarly discussed in published experiments on Alborz wild sheep habitat modeling, except to high dependency of the study species on security (proximity to eco guard' posts) which was new. Outcomes of researches done by other show that, suitable habitat for Alborz wild sheep is at elevation more than of around $1500 \mathrm{~m}$ [15] but less than of about 2000 - $2500 \mathrm{~m}$ [5], not far away water sources [27], with suitable escape terrain [15] [27], remote from human land uses including human settlements and roadways [5] [15] [27] and covered with dense vegetation, forbs and also plants taller than $0.5 \mathrm{~m}$ [27], which all supported our models of how Alborz wild sheep use landscapes of the east of Tehran. 
Maximum current maps represent the maximum amount of current flowing through each cell. Current values in these maps, ranging between 0 to 1 , reflecting landscapes' surface conductivity with high resistances allocated to movement barriers and low resistances allocated to elements that are most permeable to movement or best facilitate gene flow. Maps of maximum current uses encompass modeling movement of the study species, as well as determining areas important for connectivity between habitat patch pairs. Similarly, our map of maximum current demonstrated an overall low amount of current flow, as well as determining pinch points (bottlenecks of current) between adjacent patches. For conservation purposes, these critical connections of habitat patch pairs should be identified and prioritized over areas provide little to connectivity, since discarding or converting these connections will have high impact on network connectivity. For example, our map of current flow, showed important pinch points across Tehran-Pardis Freeway and Damavand road, where habitat patches have promoted movement of our study species between Jajrud and Varjin and Lar protected areas.

Cumulative current maps show the expected net number of dispersers' passage through each cell. These maps show which landscapes elements, including linkages and core areas habitat patches, are most important for maintaining connectivity of networks of habitat patches across study areas. For example, our map of cumulative current flow demonstrated that areas in the north of Mamloo Lake, starting from patch 6 and continuing to patches 7 play an important role in connectivity among habitats patches we modeled in our study area.

Models of centralities using Centrality Mapper determine the importance of each habitat patches and links in keeping networks connected. Our model of centrality exhibited the high significance of the large habitat patch of number 6 in connectedness of the habitats patches network. In addition, it drew our attention to the intervening smaller patches of 7 and 1 that facilitate connectivity between the larger 6 and 9 or 6 and 10. These smaller patches act as stepping-stones among larger patches for movements and gene flow between the remote patches.

Our outcomes of Alborz wild sheep habitat connectivity modeling were original. We anticipated movement pattern of this species and determined habitat patches and corridors important for conservation planning. However, results of other researches gave us a general picture of the species habitat connectivity in some parts of our study area. For example, Goljani et al. declared that wild sheep occupying Varjin protected area and Lar national park used to migrate to Jajrud protected area in the past, but nowadays the migration corridor between these two protected areas is obstructed [15]. Mashhadi Ahmadi, by applying least-cost analysis, discussed that Alborz wild sheep had seasonal movements between their habitats across province of Tehran but now their movements are restricted due to the growth of human settlements, construction and expansion of roadways, and also military sites [5]. We complemented these published results by identifying pinch points or critical habitat connections and also important habitat patches that the removal or conversion of any of these special linkages or patches would disrupt the overall connectivity of the species habitat network to a lower grade here than in another place, as well as displaying elements important for redundancy.

\section{Model Explanation of Alborz Wild Sheep Dispersal}

Our evaluation of how Alborz wild sheep are predicted to use eastern region of Tehran province can be assessed using previous studies documented dispersal of the wild sheep. These studies argue that today's migration of wild sheep is more partial than anytime. Fewer individuals migrate seasonally while more do not. Migrations are northern-southern and eastern-western, with moving into south and west in the winter and coming to the north and east in the summer. For the winter, they move in search of milder weather to the core zone of Varjin or to the hill sides of File Zamin, Khorandan, Aloun, and Arakooh and inside of the Jajrud. In summers, from there, they return towards heights of Varjin and Lar basin, for example, to the Khatun Bargah, Kafar Rah, Arou, Gol Gach, Namak Kowsar, Div Asyab and Gavinag Chal Mountains, or into altitudes of koohsefid. These seasonal movements occur through northern Jajrud that today is faced with difficulties of for e.g. cities invasion, military and industrial areas expansion, and also road ways extension (like Tehran-Pardis freeway). This may lead wild sheep's population of central and southern Jajrud become less capable of crossing such barriers [28].

This information highlights the strengths of our modeling approach for conservation planning. Our models showed position of critical linkages through which current and thus dispersal of Alborz wild sheep is intensified in narrow areas. These routs, that connectivity of winter and summer habitats depends on them, cross individuals from Arakooh (patch 7), Khorandan (patch 1), File Zamin (patch 8) to the heights of Varjin and Lar (patch 10) or vice versa. Differently, our maps showed relatively low levels of movement along Qareh Aghach Mountain stretched between Jajrud and Koohsefid. It does not mean this area is not important for movement. Oppositely, 
the wide pathway between these two implies that current are expanded across this area. Also our models showed areas of high cumulative current, important for keeping the network connected. These areas that encompass central Jajrud (above Mamloo) extending to the northern Jajrud are where their loss may bring disconnection of multiple patches of the network. Besides our models marked centrality value of habitat patches, reflecting function of each in keeping the whole network connected. Interestingly position of patches with high centrality revealed us stepping stone role of 7 and 1, for connection of 6 and 9 or 6 and 10 and the vulnerability of these two small patches to be lost as a result of development of human settlements. Overall, our models can help to understand the species present state of habitat connectivity, and to protect habitat connectedness of the network and also to predict impacts to connectivity when any of the network's elements is lost as a result of large human disturbances or natural disaster.

\section{Conclusion}

Human activities decreased available habitats of wild sheep and resulted in fewer migratory individuals, who have to move through unsuitable habitats now [15]. Effectual conservation of the species depends on land management practices that conserve continuity of habitat patches. Our identification of key habitat patches and calculations of habitat connectivity can be used to support the study species habitat connectivity conservation endeavors and also give land use planners a picture of how land use decision without full understanding of consequences of those decision, affect key ecological process such as dispersal of animal species. We believe that the approaches we outlined can be successfully used to identify core habitat areas and navigate many of the challenges in preserving habitat connectivity. The maximum-entropy principle, we applied for modeling species distribution, has been widely used since becoming available. One reason is that its predictive performance is competitive with the best performing methods. However, there is some criticism against using MaxEnt for modeling species distribution. Particularly, MaxEnt uses presence-only data rather the both presence and absence data. Indeed, it is generally recommended to use a presence-absence modelling method for the reason that presenceonly models more faced with problems of sample selection bias and the available data do not usually describe the survey method, so the user has influential leeway in defining the response variable [29]. In our case, that absence data were not available, MaxEnt worked perfectly well in modeling distribution of habitat suitability. Circuit theory, the modeling approach that we applied to estimate habitat connectivity, is known the most beneficial in compression with other approaches of analyzing origin and destination patches connectivity. Its foundation in random walk theory and the ability to evaluate contributions of multiple pathways, leads to more accurately predict how individuals move through real landscapes. However, current maps which are tools of visualizing a circuit-theoretic analysis of connectivity are difficult to interpret: for e.g. relatively lower current may imply either higher resistance in the underlying layer or presence of multiple potential dispersal routes between habitat patches [30]. Seemingly, full understanding of the study area and study species movement behavior is needed to completely comprehend connectivity maps and use them for conservation planning. Although, it was helpful for us to describe how well connected habitat patches are in our study area, where few suitable core habitat areas we mapped are surrounded by anthropogenic landscape. Our results reflect inputs acquired at coarse scale and do not include the features that may affect local movements. Approaches that involve fine scale assessments of the study species habitat use and dispersal are needed to understand how they respond to site level disturbances (such as fences in Jajrud protected area, which are increasingly erect around the areas occupied by military installations). Since experts believe that genetic deterioration of wild sheep is starting due to inbreeding which is in turn caused by habitat fragmentation, we recommend studying subpopulations genetics. This helps to validate and amend models of habitat connectivity such as ours, in order to be trustfully used in conservation planning. Lastly, to put forward on connectivity conservation efforts, studies on establishing policies for avoidance and compensation of human effects on wildlife and their habitats are advised.

\section{Acknowledgements}

The accomplishment of this study could not have been possible without the partnership and help of so many people whose names may not all be listed. Their contributions are honestly appreciated and acknowledged. However we would like to express our thankfulness particularly to the following:

Mc Rae, B; Mashhadi Ahmadi, A; Miranzadeh, E; Yeganzadeh, E; Nahidifar, H; Ebadi, R. A; Batebi, A; Shahmoradi, H; Mirza karimi, M; Mirza karimi, E; Hosseini, S; Ghasryani, F; Shirzad, M, Dehghani, V; Ahma- 
di, M; Ramezani Mehriyan, M, Rouhani, N; Mojtahedi, M; \& Sharbafi, E.

\section{References}

[1] Fischer, J. and Lindenmayer, D.B. (2007) Landscape Modification and Habitat Fragmentation: A Synthesis. Global Ecology and Biogeography 16, 265-280. http://dx.doi.org/10.1111/j.1466-8238.2007.00287.x

[2] Crooks, K.R. and Sanjayan, M.A. (2006) Connectivity Conservation: Maintaining Connections for Nature. In: Crooks, K.R. and Sanjayan, M., Eds.: Connectivity Conservation, Cambridge University Press, Cambridge, 1-20. http://dx.doi.org/10.1017/cbo9780511754821.001

[3] Bonn, A., Rodrigues, A.S.L. and Gaston, K.J. (2005) Threatened and Endemic Species: Are They Good Indicators of Patterns of Biodiversity on a National Scale? Ecology Letters, 5, 733-741. http://dx.doi.org/10.1046/j.1461-0248.2002.00376.x

[4] Moody, A., Haddad, N., Morris, W.F. and Walkters, J. (2011) Mapping Habitat Connectivity for Multiple Rare, Threatened, and Endangered Species on and around Military Installations. University of North Carolina at Chapel Hill, Chapel Hill.

[5] Mashhadi Amadi, A.A. (2014) Corridor Modeling for Centeral Alborz Wildsheep Using Least Cost Path Model in Tehran Province. M.Sc Thesis, Islamic Azad University, Science and Research Campus of Tehran, Tehran.

[6] Valdez, R. (2008) Ovis Orientalis. The IUCN Red List of Threatened Species. http://www.iucnredlist.org

[7] Rules and Regulations of Game and Fish. Department of Environment. http://www.doe.ir

[8] Data Bank of Office of Habitats and Protected Areas Affairs. Department of Environment. http://www.doe.ir

[9] Darvishsefat, A.A. (2006) Atlas of Protected Areas of Iran. University of Tehran, Tehran.

[10] Firouz, E. (2005) The Complete Fauna of Iran. 1th Edition, I.B. Tauris, New York.

[11] Ziaie, H. (2008) A Field Guide to The Mammals of Iran. 1th Edition, Iran Wildlife Center, Tehran.

[12] Tehran Provincial Directorate of Environmental Protection, 2014 Census of Mammles: Aggregate Data (Varjin Protected Area) Department of Natural Environment, Mooresville.

[13] Tehran Provincial Directorate of Environmental Protection, 2014 Census of Mammles: Aggregate Data (Koohsefid No Hunt Area) Department of Natural Environment, Mooresville.

[14] Environmental Systems Research Institute (2013) ArcMap 10.2. ESRI, Redlands.

[15] Goljani, R., Kaboli, M., Karami, M., Ghodsizadeh, Z. and Nourani, E. (2012) Male Alborz Red Sheep Migration Corridors Selection From Summer to Fall Habitats in Jajroud Protected Area Complex, Iran. Russian Journal of Ecology, 43, 67-76. http://dx.doi.org/10.1134/S1067413612010067

[16] National Cartographic Center (2002) Digital Elevation Model. Tehran, Iran.

[17] Habibi, R., Roudgarmi, P., Azhir, F. and Farahani, E. (2003) Ecological Regions of Iran: Vegetation Types of Tehran Area. Research Institute of Forests and Rangelands of Iran, Tehran.

[18] National Cartographic Center (2002) Topography. Tehran.

[19] Brown, J.L. (2014) A Python-Based GIS Toolkit for Landscape Genetic, Biogeographic and Species Distribution Model Analyses. Methods in Ecology and Evolution, 5, 694-700. http://dx.doi.org/10.1111/2041-210X.12200

[20] Minitab 17 Statistical Software (2010) Minitab, Inc., State College. http://www.minitab.com

[21] Phillips, S.J., Anderson, R.P. and Schapire, R.E. (2006) Maximum Entropy Modeling of species Geographic Distributions. Ecological Modeling, 190, 231-259. http://dx.doi.org/10.1016/j.ecolmodel.2005.03.026

[22] Phillips, S. J., Dudík, M., Schapire, R.E. (2005) Maxent Software for Species Distribution Modeling, Ver. 3.3.3k. https://www.cs.princeton.edu/ schapire/maxent/

[23] McRae, B.H., Shah, V. and Mohapatra, T. (2009) Circuitscape Software, Ver. 3.5. http://www.circuitscape.org

[24] McRae, B.H., Dickson, B.G., Keitt, T.H. and Shah, V.B. (2008) Using Circuit Theory to Model Connectivity in Ecology, Evolution, and Conservation. Ecology, 89, 2712-2724. http://dx.doi.org/10.1890/07-1861.1

[25] Dickson, B.G., Roemer, G.W., McRae, B.H. and Rundall, J.M. (2013) Models of Regional Habitat Quality and Connectivity for Pumas (Puma Concolor) in the Southwestern United States. PLoS ONE, 8, e81898.

[26] McRae, B.H. (2012) Centrality Mapper Connectivity Analysis Software, Ver. 1. http://www.circuitscape.org/linkagemapper

[27] Kermani Alghoraishi, Z., Alimohamadi Sarab, A. and Hassanzadeh Kiabi, B. (2011) Impacts of Ecological Factors on the Distribution of Wild Sheep in Khojir and Sorkhe Hessar National Parks. Iranian Journal of Natural Resources, 63, 359-372. 
[28] College of Natural Resources of university of Tehran (2009) Study of Alborz Wild Sheep Migration Routes from Lar to Varjin and Jajrud. Tehran Provincial Directorate of Environmental Protection, Tehran.

[29] Elith, J., Phillips, S.J., Hastie, T., Dudík, M., En Chee, Y. and Yates, C.J. (2011) A statistical Explanation of MaxEnt for Ecologists. Diversity and Distributions, 17, 43-57. http://dx.doi.org/10.1111/j.1472-4642.2010.00725.X

[30] Rudnick, D.A., Ryan, S.J., Beier, P., Cushman, S.A., Dieffenbach, F., Epps, C.W., Gerber, L.R., Hartter, J., Jenness, J.S., Kintsch, J., Merenlender, A.M., Perkl, R.M., Trombulak, S.C. and Preziosi, D.V. (2012) The Role of Landscape Connectivity in Planning and Implementing Conservation and Restoration Priorities. Ecological Society of America, Washington DC. 